\title{
METODOLOGIA PARA AVALIAÇÃO DO TEMPO DE COZIMENTO E CARACTERÍSTICAS TECNOLÓGICAS ASSOCIADAS EM DIFERENTES CULTIVARES DE MANDIOCA
}

\author{
Methodology for cooking and technologies analyses in different cassava's varieties \\ Marcelo Alvares de Oliveira ${ }^{1}$, Magali Leonel ${ }^{2}$, Cláudio Cabello², \\ Marney Pascoli Cereda ${ }^{2}$, Douglas Alexandre Janes ${ }^{3}$
}

\begin{abstract}
RESUMO
O consumo culinário de raízes de mandioca é bastante generalizado em todo o mundo, sendo essa raiz amplamente utilizada na forma cozida, assada, frita ou integrando pratos mais complexos. O objetivo deste trabalho foi definir metodologia, avaliar o tempo de cozimento e algumas características associadas a este processo em 26 cultivares de mandiocas. Avaliaram-se os seguintes parâmetros avaliados foram cor da entrecasca; cor da polpa; dificuldade de soltar a entrecasca; dificuldade de palitar; porcentagem de água absorvida/perdida em relação ao peso dos toletes durante o processo de cozimento; cor dos toletes cozidos; formações de pontuações brancas no interior do tolete; formação de gel em volta dos toletes e tempo de cozimento observado para cozimento de 13 palitos. Ao final da avaliação concluiu-se que as melhores cultivares para utilização como mandioca de mesa foram a SRT-1105 (Mico), Milagrosa RG, Mantiqueira, IAC 522-30, IAC 576-70, sendo a última a que apresentou melhor resultado no teste de cozimento.
\end{abstract}

Termos para indexação: mandioca, cozimento, tecnologia, raiz, Manhiot esculenta.

\begin{abstract}
The cassava roots are consumed cooked, fritted or integrating more complex foods. This work had a purpose to evaluate the cooking time and some characteristics associated to the process in 26 varieties of cassava. The parameters analyzed were color of the skin without external pellicle, color of the pulp, difficulty of peeling, difficulty of cutting, percentage of water absorbed/losted in relation to the weight of the peaces during the cooking process, color of the cooked peaces, formations of white punctuations inside the peaces, gel formation in turn of the peaces and cooking time observed to delay 13 toothpicks. The best varieties selected for use were SRT-1105 (Mico), Mantiqueira, Milagrosa RG, IAC 522-30, IAC 576-70. The IAC 576-70 showed the best results in test of cooking time.
\end{abstract}

Index terms: cassava, root, technology, cooking, Manhiot esculenta.

(Recebido para publicação em 17 de dezembro de 2003 e aprovado em 20 de outubro de 2004)

\section{INTRODUÇÃO}

O consumo culinário de raízes de mandioca é bastante generalizado em todo o mundo, sendo essa raiz amplamente utilizada na forma cozida, assada, frita ou integrando pratos mais complexos. Atualmente, a mandioca para uso culinário é comercializada como vegetal fresco ou minimamente processada, refrigerada ou congelada, ou também na forma pré-cozida facilitando o preparo e consumo.

As raízes de mandioca durante a fase de desenvolvimento da planta acumulam amido como material de reserva. O amido por não apresentar efeito osmótico nos vegetais, funciona como uma forma perfeita de reserva de açucares, pois ao ser transportado, não sofre nenhuma reação metabólica, evitando assim um gasto desnecessário para a planta. Portanto, a reserva de açú- cares nas células vegetais em forma de amido, poderia, então ser caracterizado como caráter altamente vantajoso, no ponto de vista evolutivo dos vegetais.

O amido é o constituinte mais abundante das raízes de mandioca e durante o processamento hidrotérmico sofre modificações que estão relacionadas com a gelatinização e propriedades associadas, como absorção de água e aumento do volume, tendo função importante nas características finais do produto cozido.

Fukuda e Borges (1988) afirmaram que o tempo de cozimento é um caráter importante na seleção de uma cultivar de mesa, sendo preferida àquela que apresenta menor tempo de cozimento culinário. Pereira et al. (1985) e Lorenzi (1996), também afirmaram que o tempo de cozimento é determinante na seleção de cultivares de mesa.

\footnotetext{
1. Pesquisador Dr. do CERAT/UNESP/Botucatu - Fazenda Experimental Lageado, 18603-970, Botucatu,SP - maoliveira@fca.unesp.br

2. Pesquisadores Drs. do CERAT/UNESP/Botucatu

3. Técnico Aqrícola bolsista da FAPESP no CERAT/UNESP/Botucatu
} 
A qualidade culinária das raízes de mandioca tem sido pouco estudada e as causas de sua variabilidade e instabilidade são pouco conhecidas (NORMANHA, 1988, citado por LORENZI, 1994; WHEATLEY, 1991, citado por LORENZI, 1994). As variáveis relacionadas ao cozimento que tem tido maior importância no setor da pesquisa são a textura, a plasticidade e a pegajosidade da massa, pois interferem diretamente na maioria das receitas culinárias preparadas com mandioca (PEREIRA et al., 1985). Entretanto, Lorenzi (1994) afirma que estas variáveis estão associadas à duração do tempo de cozimento (DTC), sendo que quanto menor este, melhor as qualidades sensoriais da massa gerada.

O objetivo deste trabalho foi desenvolver uma metodologia para avaliar o tempo de cozimento, assim como, características tecnológicas associadas ao mesmo em 26 cultivares de mandiocas, indicando cultivares com potencialidades para serem utilizadas como mandioca de mesa.

\section{MATERIAL E MÉTODOS}

\section{Matéria Prima}

As cultivares foram obtidas do Campo Experimental do Departamento de Genética da ESALQ, localizado no município de Anhembi, SP. As raízes foram colhidas manualmente, durante os dias 29 de janeiro de 2001 e 22 de fevereiro de 2001, retirando-se uma planta inteira de cada cultivar da coleção. A indicação e o estado de origem de cada cultivar estão descritos na Tabela 1.

As cultivares estudadas serviram de parâmetros para estudos de teste de cozimento e mesmo algumas cultivares não sendo indicadas para mesa, mediante este trabalho, verificamos que algumas poderão ser cultivadas para este fim, ou serem adicionadas em programas de melhoramento para lançamento de novas cultivares.

\section{Análises visuais e físicas}

As raízes foram lavadas e descascadas e os parâmetros avaliados foram cor da entrecasca (branca, creme, amarela, rosa e roxa), cor da polpa (branca, creme e amarela), dificuldade de retirada da entrecasca (fácil, média, difícil), dificuldade de cortar em palitos em palitador manual (fácil, média e difícil), sendo todos esses parâmetros de forma subjetiva e avaliados pelos os autores.

\section{Análises de cozimento}

As análises referentes ao cozimento das raízes foram porcentagem de água absorvida/perdida em relação ao peso dos toletes durante o processo de cozimento, sendo os toletes pesados antes e após o cozimento; cor dos toletes cozidos; formações de pontuações brancas no interior do tolete (sem pontuações, poucas pontuações e muitas pontuações); formação de gel em volta dos toletes (pouca, média e bastante) e tempo de cozimento observado para cozimento de 13 palitos. Determinou-se o tempo de cozimento foi determinado em um cozedor Mattson modificado e adaptado para avaliar cozimento de mandioca (OLIVEIRA et al., 2001). O equipamento é feito em aço inox, composto de 24 pinos, cada pino está calibrado a $40 \mathrm{~g}$. A calibração é feita no topo do pino, onde uma cápsula rosqueada recebe chumbinhos. Esses pinos deslizam sobre duas placas perfuradas, de forma a se posicionarem sobre os palitos de mandioca. Com o cozimento eles penetram nos palitos de mandioca e afundam, sendo então contados (Figura 1).

Colocou-se o aparelho dentro de um recipiente metálico de $25 \mathrm{~cm}$ de diâmetro com 7 litros de água. As raízes descascadas foram cortadas em toletes com $3 \mathrm{~cm}$ de comprimento. Com uma máquina manual de cortar legumes, com grade de 10 milímetros, cortaram-se os palitos de 10x10x30 mm. Os 24 pinos foram posicionados de forma a tocar os pedaços sob cada pino. Com a água fervendo $\left(97,4^{0} \mathrm{C}\right.$, altitude de $800 \mathrm{~m}$ do município de Botucatu), colocou-se o equipamento todo no recipiente. A água fervente cobriu todos os palitos de mandioca e marcou-se o tempo de início do teste. Considerouse como tempo de cozimento o momento da queda $50 \%$ dos pinos mais um, ou seja, o tempo necessário para que caíssem 13 pinos. Após 30 minutos o teste foi finalizado, retirando-se o aparelho do recipiente e verificandose a posição dos pinos.

\section{Análise do teor de amido das raízes}

Uma amostra de raiz de cada cultivar foi desidratada em estufa de circulação de ar a $55^{\circ} \mathrm{C}$, determinando-se a umidade inicial de cada amostra (AOAC, 1970). Para a determinação do teor de amido nas raízes de mandioca utilizou-se o método enzimático de hidrólise. Pesou-se 200mg de amostra desidratada finamente peneirada $(0,25 \mathrm{~mm})$ e acrescentou-se $42 \mathrm{~mL}$ de água. 
TABELA 1 - Cultivares, indicação, e estado de origem de raízes de mandioca cultivadas no campo experimental do Departamento de Genética da ESALQ.

\begin{tabular}{|c|c|c|}
\hline Cultivar & Indicação & Origem \\
\hline SRT - 105 (Мico) & Mesa & SP \\
\hline Mandioca 645 & Farinha & PA \\
\hline BGM 019 & Farinha & PA \\
\hline Orenina & Farinha & $\mathrm{PA}$ \\
\hline Amarela amariacu & Farinha & PA \\
\hline $\mathrm{EAB}-688$ & Farinha & BA \\
\hline Osso duro & Farinha & PA \\
\hline Agami & Farinha & PA \\
\hline Sutiga & Ração Animal & PA \\
\hline $\mathrm{EAB}-1121$ & Farinha & BA \\
\hline Cultivar precoce & Farinha & $\mathrm{PA}$ \\
\hline Mantiqueira - 0211 & Farinha & SP \\
\hline Clone 4919 & Farinha & PA \\
\hline Ereta & Mesa & $\mathrm{PA}$ \\
\hline Milagrosa RG & Farinha & PA \\
\hline Mantiqueira & Farinha & $\mathrm{PA}$ \\
\hline CPM - 1425 & Farinha & $\mathrm{AM}$ \\
\hline IAC $522-30$ & Farinha & SP \\
\hline Olho roxo de Alamira & Farinha & PA \\
\hline Witadehemesik & Farinha & $\mathrm{PA}$ \\
\hline Pão Manaus & Mesa & $\mathrm{AM}$ \\
\hline Macaxeirão & Mesa & PA \\
\hline IAC $576-70$ & Farinha/Mesa & SP \\
\hline Mameluca & Farinha & PA \\
\hline $\mathrm{IM}-186$ & Farinha & PA \\
\hline Boa Fama & Mesa & RO \\
\hline
\end{tabular}

Ciênc. agrotec., Lavras, v. 29, n. 1, p. 126-133, jan./fev. 2005 


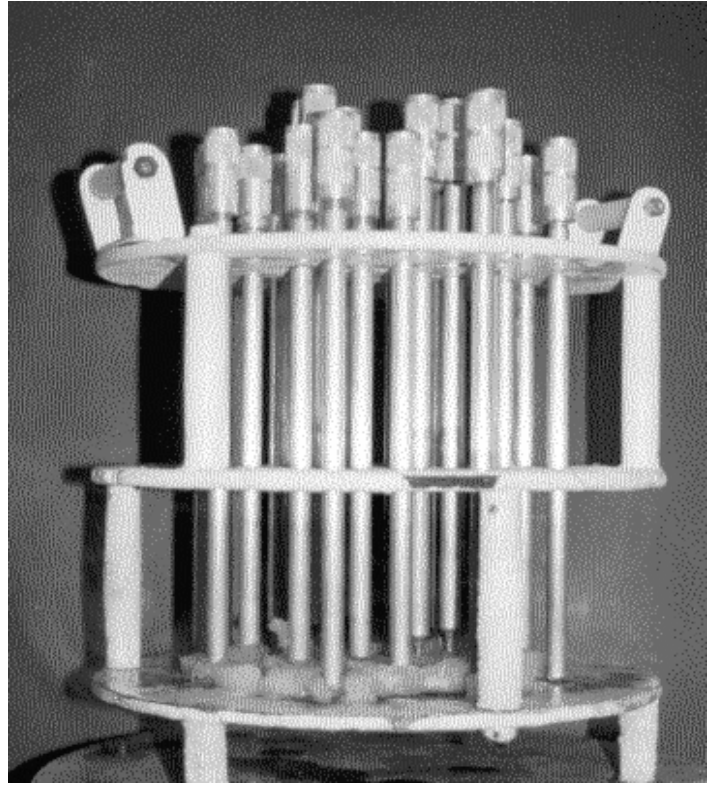

FIGURA 1 - Equipamento Mattson modificado e utilizado para proceder ao teste de cozimento em toletes de mandioca.

Para a hidrólise inicial utilizou-se $2 \mathrm{~mL}$ de Termamyl 120L ( $\alpha$-amilase), inclusive na prova em branco, e levou-se em banho-maria com agitação na temperatura de $90^{\circ} \mathrm{C}$ por 15 minutos. Decorrido este período esperou-se abaixar a temperatura para $60^{\circ} \mathrm{C}$ e adicionaram-se 2,5 mL de tampão acetado 4M, pH 4,8 e em seguida $2 \mathrm{~mL}$ de solução de amiloglucosidase na concentração de $1,5 \mathrm{mg} / \mathrm{mL}$. O material permaneceu a $60^{\circ} \mathrm{C}$ no banho com agitação por 2 horas (RICKARD e $\mathrm{BEHN}$, 1987). Após o material ser resfriado determinou-se o teor de açúcar, sendo feita a conversão à amido pela multiplicação da porcentagem de açúcar obtida pelo fator 0,9 (SOMOGY, 1945).

\section{RESULTADOS E DISCUSSÃO}

\section{Análises visuais e físicas}

As diferenças de coloração de entrecasca e polpa foram bastante variáveis entre as cultivares. Em relação às análises feitas antes do teste de cozimento propriamente dito, a cultivar Mandioca 645 do Pará, foi previamente descartada para a utilização como mandioca de mesa, devido à grande dificuldade da retirada da entrecasca, já que não existe descascador eficiente que possa ser utilizado para retirar a casca e entrecasca da mandioca. As cultivares Agâmi, Sutigá, Cultivar Precoce, Ereta, Olho roxo de Alamira e Pão de Manaus (todas de origem no Pará) e ainda a cultivar EAB-1121 (Bahia) apresentaram média dificuldade de retirada da entrecasca, fator considerado negativo na seleção de cultivares para mesa. As demais cultivares não apresentaram problemas em relação a este atributo (Tabela 2).

A dificuldade de cortar em palitos está relacionada com a dificuldade de cortar a raiz, que resultará em dificuldade para o consumidor no preparo culinário. Já para a indústria esta etapa exige a utilização de equipamentos que terão a vida útil prejudicada. As cultivares Watadehemesik e Mameluka foram as que apresentaram maior grau de dificuldade para palitar, acarretando problemas em relação ao corte das mesmas (Tabela 2).

A dificuldade de retirada da entrecasca e a dificuldade de palitar são pontos não relatados na literatura em relação ao cozimento, entretanto, quando se analisa a cadeia como um todo, verifica-se que o consumidor necessita de um produto que solte a entrecasca com facilidade. Mesmo que este produto seja processado em uma indústria, este parâmetro é um problema, pois para esta etapa do processo, praticamente não existe maquinário adequado e na grande maioria das vezes o mesmo é feito manualmente. Portanto, as melhores cultivares selecionadas tomando-se como base os dois atributos supracitados foram às cultivares SRT-1105 (Mico), BGM-019, EAB - 688, Mantiqueira - 0211, Mantiqueira, IAC 522-30, IAC 576-70 e IM - 186.

\section{Análises de cozimento}

Os resultados obtidos no teste de cozimento das raízes de mandioca estão apresentados na Tabela 3. 
TABELA 2 - Atributos de coloração da casca e polpa, dificuldade de retirada da entrecasca e de cortar em palitos das cultivares de mandioca cultivadas no campo experimental do Departamento de Genética da ESALQ.

\begin{tabular}{|c|c|c|c|c|}
\hline Cultivares & $\begin{array}{c}\text { Cor da } \\
\text { Entrecasca }\end{array}$ & $\begin{array}{c}\text { Cor da } \\
\text { Polpa }\end{array}$ & $\begin{array}{c}\text { Dificuldade de } \\
\text { Retirada daEntrecasca }\end{array}$ & $\begin{array}{c}\text { Dificuldade de } \\
\text { Cortar em Palitos }\end{array}$ \\
\hline Srt - 105 (Mico) & Creme & Branca & Fácil & Média Dificuldade \\
\hline Mandioca 645 & Branca & Branca & Difícil & Fácil \\
\hline Bgm 019 & Amarela & Amarela & Fácil & Fácil \\
\hline Orenina & Creme & Creme & Fácil & Média Dificuldade \\
\hline Amarela Amariacu & Creme & Branca & Fácil & Média Dificuldade \\
\hline$E a b-688$ & Creme & Creme & Fácil & Fácil \\
\hline Osso Duro & Branca & Branca & Fácil & Média Dificuldade \\
\hline Agami & Amarela & Amarela & Média Dificuldade & Fácil \\
\hline Sutiga & Creme & Branca & Média Dificuldade & Média Dificuldade \\
\hline Eab - 1121 & Branca & Branca & Media Dificuldade & Fácil \\
\hline Cultivar Precoce & Amarela & Amarela & Média Dificuldade & Fácil \\
\hline Mantiqueira - 0211 & Roxa & Branca & Fácil & Fácil \\
\hline Clone 4919 & Creme & Creme & Fácil & Média Dificuldade \\
\hline Ereta & Creme & Amarela & Média Dificuldade & Fácil \\
\hline Milagrosa RG & Roxa & Branca & Fácil & Média Dificuldade \\
\hline Mantiqueira & Rosa & Branca & Fácil & Fácil \\
\hline Com - 1425 & Branca & Branca & Fácil & Média Dificuldade \\
\hline IAC 522-30 & Branca & Branca & Fácil & Fácil \\
\hline Olho Roxo De Alamira & Branca & Branca & Média Dificuldade & Fácil \\
\hline Witadehemesik & Creme & Creme & Fácil & Difícil \\
\hline Pão Manaus & Creme & Branca & Média Dificuldade & Média Dificuldade \\
\hline Macaxeirão & Branca & Branca & Fácil & Difícil \\
\hline IAC 576-70 & Creme & Creme & Fácil & Fácil \\
\hline Mameluca & Creme & Creme & Fácil & Difícil \\
\hline $\mathrm{IM}-186$ & Creme & Creme & Fácil & Fácil \\
\hline Boa Fama & Creme & Creme & Fácil & Média Dificuldade \\
\hline
\end{tabular}

Ciênc. agrotec., Lavras, v. 29, n. 1, p. 126-133, jan./fev. 2005 
TABELA 3 - Teste para cozimento de raízes de mandiocas cultivadas no campo experimental do Departamento de Genética da ESALQ.

\begin{tabular}{|c|c|c|c|c|c|}
\hline \multirow[b]{2}{*}{ Cultivares } & \multicolumn{5}{|c|}{ Parâmetros } \\
\hline & $\begin{array}{l}\text { \% de água ab- } \\
\text { sorvida / perdida } \\
\text { pelos toletes }\end{array}$ & $\begin{array}{c}\text { Cor dos toletes } \\
\text { zidos }\end{array}$ & $\begin{array}{l}\text { Pontos brancos no in- } \\
\text { terior dos toletes }\end{array}$ & $\begin{array}{c}\text { Formação de } \\
\text { gel em volta dos } \\
\text { toletes }\end{array}$ & $\begin{array}{c}\text { Porcentagem de } \\
\text { palitos cozidos } \\
\text { em até } 30 \mathrm{~min}\end{array}$ \\
\hline $\begin{array}{l}\mathrm{SRT}-105 \\
\text { (Mico) }\end{array}$ & $+30,85$ & Creme/Amarelados & Poucos & Bastante & 20,00 \\
\hline Mandioca 645 & $-4,60$ & Brancos & Sem Pontos & Pouca & 0,00 \\
\hline BGM 019 & $-2,37$ & Amarelos & Sem Pontos & Pouca & 10,00 \\
\hline Orenina & $+8,16$ & Amarelos & Sem Pontos & Média & 0,00 \\
\hline $\begin{array}{l}\text { Amarela } \\
\text { amariacu }\end{array}$ & $+1,61$ & Brancos & Poucos & Média & 0,00 \\
\hline $\mathrm{EAB}-688$ & $-2,68$ & Amarelos & Sem Pontos & Pouca & 0,00 \\
\hline Osso duro & $+9,84$ & Cremes & Muitos & Bastante & 0,00 \\
\hline Agami & $-10,97$ & Amarelos & Sem Pontos & Nenhuma & 0,00 \\
\hline Sutiga & $+1,60$ & Cremes & Poucos & Pouca & 0,00 \\
\hline EAB - 1121 & $+19,30$ & Creme/ Amarelados & Muitos & Média & 0,00 \\
\hline $\begin{array}{l}\text { Cultivar } \\
\text { precoce }\end{array}$ & $-5,49$ & Amarelos & Sem Pontos & Pouca & 0,00 \\
\hline $\begin{array}{l}\text { Mantiqueira - } \\
0211\end{array}$ & $+29,94$ & Cremes & Muitos & Média & 23,33 \\
\hline Clone 4919 & $+6,51$ & Creme/ Amarelados & Sem Pontos & Média & 0,00 \\
\hline Ereta & $-5,94$ & Amarelos & Sem Pontos & Pouca & 0,00 \\
\hline Milagrosa RG & $+37,06$ & Cremes & Poucos & Bastante & 36,67 \\
\hline Mantiqueira & $+16,48$ & Brancos & Poucos & Bastante & 10,00 \\
\hline COM - 1425 & $+2,54$ & Cremes & Sem Pontos & Pouca & 0,00 \\
\hline IAC 522 - 30 & $+20,69$ & Cremes & Poucos & Bastante & 36,67 \\
\hline Olho roxo & $-12,19$ & Amarelos & Sem Pontos & Nenhuma & 0,00 \\
\hline Alamira & & & & & \\
\hline Witadehemesik & $+0,90$ & Cremes & Sem Pontos & Pouca & 0,00 \\
\hline Pão Manaus & $+3,18$ & Cremes & Poucos & Pouca & 0,00 \\
\hline Macaxeirão & $+4,41$ & Brancos & Poucos & Pouca & 0,00 \\
\hline IAC $576-70$ & $+16,68$ & Creme/ Amarelados & Sem Pontos & Bastante & $>50 \%$ (28 Min) \\
\hline Mameluca & $-1,56$ & Amarelos & Sem Pontos & Nenhuma & 0,00 \\
\hline $\mathrm{IM}-186$ & $-0,56$ & Amarelos & Sem Pontos & Nenhuma & 0,00 \\
\hline Boa Fama & $-5,00$ & Amarelos & Sem Pontos & Nenhuma & 0,00 \\
\hline
\end{tabular}


A análise da porcentagem de água absorvida/perdida pelas raízes mostrou um aumento significativo nos pesos dos toletes após o cozimento, ocorrendo absorção de água e conseqüentemente maior gelatinização dos grânulos de amido dentro das células. Assim sendo, esses toletes apresentaram uma textura mais macia e maior pegajosidade, o que está de acordo com Pereira et al. (1985) e Lorenzi et al. (1990), que afirmaram que a pegajosidade é um atributo importante a ser analisado durante o cozimento de raízes de mandioca.

As cultivares que apresentaram uma maior porcentagem de água absorvida pelos toletes com melhores características de pegajosidade foram SRT-1105 (Mico), EAB - 1121, Mantiqueira - 0211, Milagrosa RG, Mantiqueira, IAC 522-30 e IAC 576-70.

Em relação à coloração do tolete depois do cozimento verificou-se que as cultivares Watadehemesik e Macaxeirão foram reprovadas, pois na coloração dos toletes apareceram pontuações escuras que inviabilizam a utilização destes cultivares para mesa. Outro ponto importante a ressaltar é a preferência do consumidor do estado de São Paulo por mandioca de mesa de coloração amarela e do consumidor dos estados do Norte e Nordeste pela coloração creme.

A formação de pontuações brancas no interior dos toletes indica baixa gelatinização do amido. Fukuda e Borges (1988) utilizaram esta classificação de outra forma, isto é, por meio do amassamento da massa cozida com garfo e verificação de encaroçamento que reflete as pontuações brancas no interior dos toletes. Durante o cozimento o importante é que não ocorra a formação destas pontuações. As cultivares em que ocorreram muitas pontuações brancas foram a Osso duro, EAB - 1121 e Mantiqueira - 0211.

A formação de gel em volta dos toletes é outro fator importante dentro do cozimento, pois a maior formação de gel indica a ocorrência de ruptura das paredes celulares durante o processo de cozimento, ocorrendo o contato de todo o amido com a água em ebulição, o que leva ao processo de gelatinização do mesmo, fator de importância no processo. As cultivares SRT - 105 (Mico), Osso Duro, Milagrosa RG, Mantiqueira, IAC 522 30 , IAC 576 - 70 foram as que apresentaram maior formação de gel em volta dos toletes. Fukuda e Borges (1988) classificaram este item em pegajosidade e plasti- cidade. Quanto mais pegajoso os toletes, maior a formação de gel em volta dos mesmos e quanto maior a plasticidade, menor a formação de gel em volta das raízes.

O uso do cozedor Mattson na metodologia para determinação do tempo de cozimento propiciou uma avaliação mais objetiva do que a proposta por Pereira et al. (1985), e seguida por Fukuda et al. (1988), Carvalho et al. (1988) e Lorenzi et al. (1990, 1996), em que o cozimento era avaliado de forma subjetiva, com auxílio de um garfo. Com relação ao tempo de cozimento necessário para cair 13 palitos (Tabela 3) verificou-se, que apenas na cultivar IAC 576-70 ocorreu o caimento dos 13 palitos em menos de 30 minutos. Para as cultivares SRT - 1105 (Mico), BGM 019, Mantiqueira - 0211, Milagrosa RG, Mantiqueira, IAC 522 - 30 também ocorreram cozimento de palitos após 30 minutos, entretanto, não atingiu o valor de $50 \%+1$. As demais cultivares foram reprovadas neste atributo e consideradas impróprias para cozimento.

\section{Análises do teor de amido das raízes}

A análise do teor de amido nas raízes demonstrou grande variação deste parâmetro entre as cultivares de mandioca, ocorrendo raízes com teores muito baixos $(<10 \%)$ e cultivares com teores bastante elevados (> $30 \%$ ). Pela Figura 2 pode-se observar os dados da porcentagem de amido na raiz e da formação de gel em volta dos toletes.

A porcentagem de amido na raiz está relacionada com a pegajosidade, pois um alto teor de amido na raiz tende a aumentar a formação de gel em volta dos toletes. Entretanto, este não é o único parâmetro associado à formação de gel em volta dos toletes, pois as cultivares Mameluca, IM - 186 e Boa Fama apresentaram altos teores de amido sem apresentarem formação de gel em volta dos mesmos.

As cultivares em que ocorreram maiores formações de gel em volta dos toletes foram a SRT - 1105 (Mico), Osso duro, Milagrosa RG, Mantiqueira, IAC 522-30 e IAC 576-70, sendo que a faixa de teor de amido destas raízes variou de $23,26 \%$ a 33,09\% (Figura 2), teor este considerado um elevado teor de amido. Assim sendo, o teor de amido é um fator a ser considerado para a seleção de uma mandioca de mesa. 


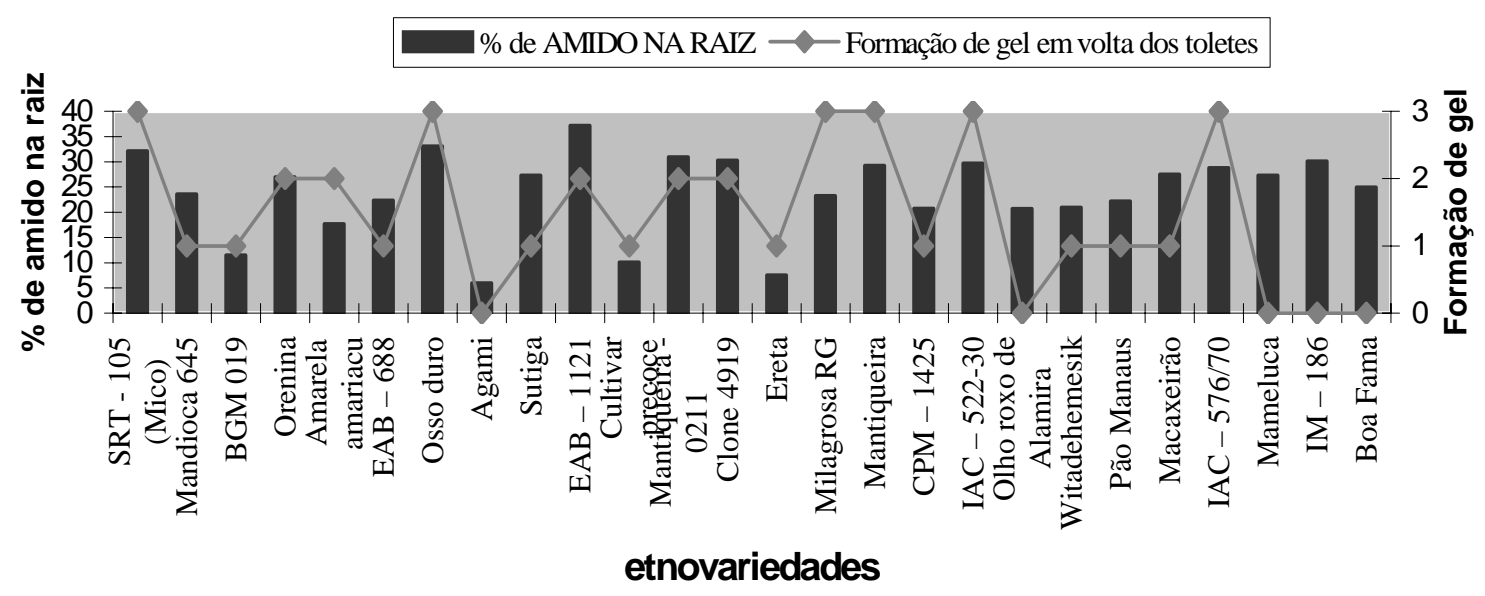

FIGURA 2 - Relação entre \% de amido na raiz e formação de gel em volta dos toletes de mandioca ( 0 - Nenhuma; 1- Pouca; 2 - Média; 3- Bastante) cultivadas no campo experimental do Departamento de Genética da ESALQ.

\section{CONCLUSÕES}

A partir dos resultados obtidos foi possível concluir que as cultivares SRT - 1105 (Mico), Milagrosa RG, Mantiqueira, IAC 522-30 e IAC 576-70 podem ser indicadas como mandioca de mesa, com base nos parâmetros utilizados neste trabalho. Todas as cultivares atingiram pontos satisfatórios em relação às análises visuais, físicas, teste de cozimento e porcentagem de amido. O inconveniente da Milagrosa RG é a média dificuldade de retirar a casca e da SRT - 1105 (Mico) a menor porcentagem de palitos cozidos em 30 minutos. A IAC 576-70 é a melhor cultivar das testadas, visto que foi a única cultivar em que ocorreu mais de $50 \%$ de palitos cozidos em menos de 30 minutos.

\section{REFERÊNCIAS BIBLIOGRÁFICAS}

ASSOCIATION OF OFFICIAL ANALYTICAL CHEMISTS. Official methods as analysis of the association of official analytical chemists. 11. ed. Washington, 1970. $1015 \mathrm{p}$.

CARVALHO, P. C. L. de et al. Avaliação agronômica e tecnológica de cultivares de mandioca para consumo "in natura”. Revista Brasileira de Mandioca, Cruz das Almas, v. 7, n. 2, p. 7-18, 1988.

FUKUDA, W. M. G.; BORGES, M. F. Avaliação qualitativa de mandioca de mesa. Revista Brasileira de Mandioca, Cruz das Almas, v. 7, n. 1, p. 63-71, 1988.

FUKUDA, W. M. G.; SILVA, R. C. A.; BORGES, M. F. Seleção de cultivares de mandioca para o consumo "in natura”. Revista Brasileira de Mandioca, Cruz das Almas, v. 7, n. 2, p. 7-18, 1988.

LORENZI, J. O. Variação na qualidade culinária das raízes de mandioca. Bragantia, Campinas, v. 53, n. 2, p. 237-245, 1994.

LORENZI, J. O. et al. Testes regionais de cultivares de mandioca de mesa no estado de São Paulo. Bragantia, Campinas, v. 49, n. 2, p. 391-401, 1990.

LORENZI, J. O. et al. Avaliação de cultivares de mesa do Vale do Ribeira (SP). Bragantia, Campinas, v. 55, n. 1, p. 141-146, 1996.

OLIVEIRA, M. A. et al. Comportamento físico, químico e culinário de raízes de mandioca cv IAC 576-70, processadas como "minimamente processadas", tratadas com ácido cítrico e hipoclorito de sódio e embaladas à vácuo em sacos de polietileno, por 4 semanas à 40 C. In: Simpósio Latinoamericano de Raíces e Tuberculos, 2., 2001, Lima, Peru. Anais... Molina: Universidad Nacional Agrária La Molina, 2001. p. 11.

PEREIRA, A. S.; LORENZI, J. O.; VALLE, T. L. Avaliação do tempo para cozimento e padrão de massa cozida em mandioca de mesa. Revista Brasileira de Mandioca, Cruz das Almas, v. 47, n. 1, p. 27-32, 1985.

RICKARD, J. E.; BEHN, K. R. Evaluation of acid and enzyme hydrolitic methods for determination of cassava starch. Journal Science Food Agriculture, London, v. 41, p. 373 -379, 1987.

SOMOGY, M. Determination of blood sugar. Journal Biology Chemical, Baltimore, n. 160, p. 69-73, 1945. 
